\title{
Erratum to: Complex Regional Pain Syndrome: What Specialized Rehabilitation Services Do Patients Require?
}

\author{
I. Elias Veizi • Thomas C. Chelimsky • Jeffrey W. Janata
}

Published online: 4 July 2012

(C) Springer Science+Business Media, LLC 2012

Erratum to: Curr Pain Headache Rep (2012) 16:139-46

DOI 10.1007/s11916-012-0253-3

The original version of this article was published in the April 2012 issue of Current pain and Headache Reports (volume 16, issue 2).

The term "chronic regional pain syndrome" should be read as "complex regional pain syndrome" in the title, abstract, and keywords.

The online version of the original article can be found at http:// dx.doi.org/10.1007/s11916-012-0253-3.

I. E. Veizi $\cdot$ J. W. Janata $(\bowtie)$

Departments of Psychiatry and Anesthesiology,

University Hospitals Case Medical Center,

11100 Euclid Avenue,

Cleveland, OH 44106, USA

e-mail: jeffrey.janata@case.edu

T. C. Chelimsky

Department of Neurology, Medical College of Wisconsin,

9200 West Wisconsin Avenue,

Milwaukee, WI 53226, USA 